\title{
Decoding the Social World
}

\author{
Sandra González-Bailón \\ Annenberg School for Communication \\ University of Pennsylvania \\ sgonzalezbailon@asc.upenn.edu
}

\begin{abstract}
Social life is full of paradoxes. Our intentional actions often trigger outcomes that we did not intend or even envision. How do we explain those unintended effects and what can we do to regulate them? In this talk, I will discuss research that illustrates how data science and digital traces help us solve the puzzle of unintended consequences-offering the solution to a social paradox that has intrigued thinkers for centuries. Communication has always been the force that makes a collection of people more than the sum of individuals, but only now can we explain why: digital technologies have made it possible to parse the information we generate by being social in new, imaginative ways. Yet we must look at that data, I will argue, through the lens of theories that capture the nature of social life. The technologies we use, in the end, are also a manifestation of the social world we inhabit.
\end{abstract}

In this talk I will discuss how the unpredictability of social life relates to communication networks, social influence, and the unintended effects that derive from individual decisions. I will focus on empirical research in the field of political communication, with special emphasis on the analysis of social media, mobilization dynamics, exposure to information, and news consumption. I will describe how communication generates social dynamics in aggregate (leading to episodes of "collective effervescence") and I will discuss the mechanisms that underlie large-scale diffusion, when information and behavior spread "like wildfire." I will use the theory of networks to illuminate why collective outcomes can differ drastically even when they arise from the same individual actions. By opening the black box of unintended effects, and how they relate to communication dynamics, I hope to identify strategies for social intervention and illuminate policy implications-and how data science and the analysis of digital traces embolden critical thinking in a world that is constantly changing.

\section{CCS Concepts/ACM Classifiers}

Collaborative and social computing; social networks; social media; social network analysis; behavioral sciences; sociology.

\section{Author Keywords}

Computational social science; networks; political communication.

Permission to make digital or hard copies of part or all of this work for personal or classroom use is granted without fee provided that copies are not made or distributed for profit or commercial advantage and that copies bear this notice and the full citation on the first page. Copyrights for third-party components of this work must be honored. For all other uses, contact the Owner/Author.

WebSci '19, fune 30-7uly 3, 2019, Boston, MA, USA

(C) 2019 Copyright is held by the owner/author(s)

ACM ISBN 978-1-4503-6202-3/19/06

https://doi.org/10.1145/3292522.3326059

\section{BIOGRAPHY}

Sandra González-Bailón is an Associate Professor at the Annenberg School for Communication, University of Pennsylvania, and affiliated faculty at the Warren Center for Network and Data Sciences. Prior to joining Penn, she was a Research Fellow at the Oxford Internet Institute, where she is now a Research Associate. Her research lies at the intersection of network science, data mining, computational tools, and political communication. She is the author of the book Decoding the Social World (MIT Press) and co-editor of The Oxford Handbook of Networked Communication (OUP). She is an associate editor of the journals Social Networks, EPf Data Science, and the International Journal of Press/Politics.

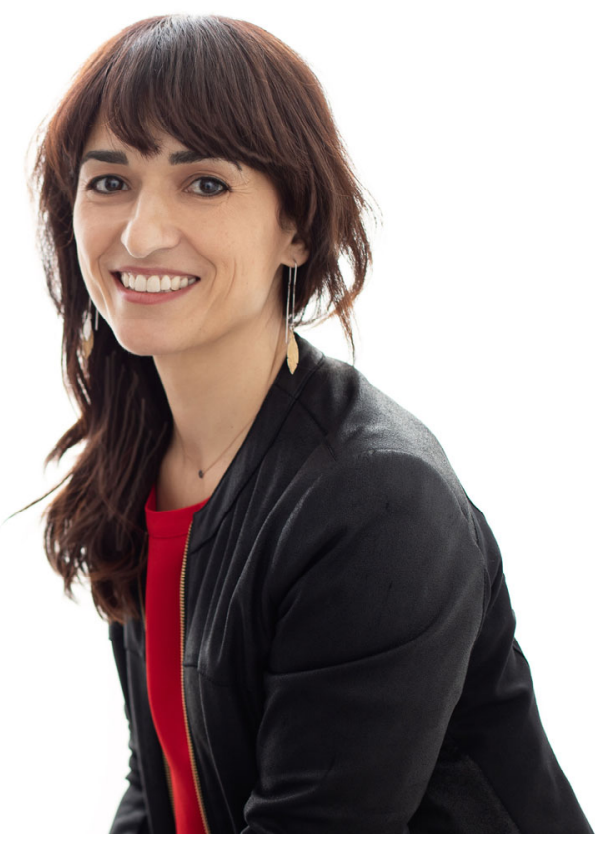

\section{REFERENCES}

[1] González-Bailón, S. (2017). Decoding the Social World. Data Science and the Unintended Consequences of Communication, Boston, MA: MIT Press.

[2] Foucault-Welles, B. and González-Bailón, S. (eds.) (2018). The Oxford Handbook of Networked Communication, Oxford: Oxford University Press. 